\title{
From Imitation to Innovation: A Study of China's Drug R\&D and Relevant National Policies
}

\author{
Jingxi Ding', Yajiong Xue ${ }^{2}$, Huigang Liang ${ }^{3}$, Rong Shao ${ }^{4}$, Yongfa Chen ${ }^{5}$
}

\begin{abstract}
Research \& Development (R\&D) plays an increasingly important role in China's pharmaceutical industry. To gain a competitive edge in the global pharmaceutical market, the current national strategy of China forcefully pushes for independent drug innovations. This article investigates the historical, legal, and institutional contexts in which China's drug R\&D has evolved. Based on an analysis of the drug R\&D evolution and national policies in China, it predicts the future trend of China's policies relevant to drug innovations. This paper helps to understand the impact of national policies on drug R\&D in China, which can be used to inform decision-making on investments in China's pharmaceutical market or conducting technology trade and international cooperation with Chinese partners.
\end{abstract}

Keywords: R\&D; drug innovation; patent law; intellectual property; China; pharmaceutical industry.

\footnotetext{
' LLD, School of International Pharmaceutical Business, China Pharmaceutical University Nanjing, Jiangsu 21 I I98, China Email: dingjinxi@yahoo.com.cn

${ }^{2} \mathrm{PhD}$, Center for Healthcare Management Systems, College of Business, East Carolina University Greenville, NC 27858, USA

Email:yajiong.xue@gmail.com

${ }^{3}$ Corresponding author, PhD, Center for Healthcare Management Systems, College of Business, East Carolina University Greenville, NC 27858, USA Phone: 252-737-I 462 Email:yajiong.xue@gmail.com

${ }^{4}$ MS, School of International Pharmaceutical Business, China Pharmaceutical University, Nanjing, Jiangsu 21 I 198, China Email: shaorongl18@163.com

${ }^{5}$ PhD, School of International Pharmaceutical Business, China Pharmaceutical University, Nanjing, Jiangsu 21 I I 98, China Email: cyf990@163.com
} 


\section{Introduction}

China's pharmaceutical industry has developed rapidly with its booming economy. Since China's reform and opening-up in 1978, the pharmaceutical industrial output value has been increasing at an average annual growth ratio of $16.6 \%$. Along with this remarkable growth, China's pharmaceutical industry has switched its focus of drug discovery from imitation to innovation so that its drug products are more competitive in the global market.

Drug R\&D is a risky business characterized by large investments, long duration, low success ratios, and high technical spillover ( $\mathrm{Li}, 2007)$. While a number of ways can be employed to spur drug R\&D, the experience of developed countries indicates that government regulations, incentives, and policies play a prominent role in augmenting a country's drug R\&D capabilities (Du, 2005). The Chinese government has been deeply involved with nurturing its drug R\&D capabilities by creating an innovation-oriented environment. National policies have inevitably shaped the evolution path of China's drug R\&D.

Bartlett and Ghosal (2000) created the pharmaceutical industry value curve to help understand how companies evolve into certain product segments. The pharmaceutical product market can be viewed as a collection of segments: some are more profitable than others. To compete in the more profitable segments requires more sophisticated and complex R\&D capabilities. As technological complexity of a product segment increases, its gross margin is enlarged. When companies have no capabilities to deal with technologically complex products, they have to stay at the lower end of the curve. Once they are capable of developing more complex products, they are likely to move up the curve to enter a more profitable segment. The pharmaceutical industry value curve is consistent with the knowledge-based view of firms which posits that knowledge is the most important organizational asset determining superior firm performance (Grant, 1996).

Based on the pharmaceutical industry value curve and a case study, this article intends to answer two research questions: (I) how China's drug innovation evolved and (2) what are China's current national strategy and policy systems that influence its drug innovation? It investigates the historical, legal, and institutional contexts in which China's drug R\&D have taken place. Based on an analysis of the evolution of drug R\&D, and incentive policy systems of
IPR in China, it predicts the future trend of drug innovation policies in China. It provides a rich understanding of the national policies relevant to drug innovations, which can be used to help developing countries design appropriate policies to motivate drug innovations and help companies make decisions on investing in China's pharmaceutical market or conducting technology trade and international cooperation with Chinese partners.

The following section describes the methodology of this study. At first the methodology is described. The results are reported next - specifically, the phased evolution of drug innovation in China, the R\&D level and important policies in each phase, and the national drug innovation strategy and policy system are described and analyzed. In the discussion section, we discuss China's policy trends relevant to drug innovation. Finally, the conclusion section ends the paper.

\section{Methods}

Given the descriptive and exploratory nature of this study, we employed a qualitative research method to collect secondary data (Yin, 2003). The data were collected from four sources to obtain a complete set of information regarding China's drug R\&D evolution. First, we collected official data from government reports and databases including the China Medicine Yearbook, China's Advanced Technology Industry Census, China's Science and Technology Statistics, annual reports of the State Food and Drug Administration of China (SFDA) and Food and Drug Administration of the United States (FDA), and patent databases of State Intellectual Property Office of China (SIPO), United States Patent and Trademark Office (USPTO), Japan Patent Office (JPO), and European Patent Office (EPO). Second, we retrieved relevant information by searching industrial databases including China's Medicine Economics Information Network, European Federation of Pharmaceutical Industries and Associations (EFPIA), Pharmaceutical Research and Manufacturers of America (PhRMA), and Japan Pharmaceutical Manufacturers Association (JPMA). Third, we reviewed all of the laws, regulations, and national policies related to pharmaceuticals, patents, and science and technology from 1991 to 2009. Finally, we downloaded documents from a number of pharmaceutical companies from which the evolution of China's drug R\&D can be inferred. The data gathered from different sources were integrated along the timeline of China's R\&D evolution. 
Since the majority of the data we collected are not structured, it was difficult to search the data using specific keywords. Instead, two authors read all of the documents to retrieve information on drug-related R\&D, innovation, patent, intellectual property, regulations, laws, and policies. The information was organized in a chronological order. Charts were drawn to show the major events, key statistics and relevant laws and policies along a time axis. Using the pharmaceutical industry value curve (Bartlett \& Ghosal, 2000) as a framework, the authors defined drug R\&D phases through individual reflection on the data and several rounds of debates until agreement was achieved. Once the phases were determined, we organized the data into each phase and examine how the phase was characterized by the key events that occurred in that period. Applying the triangulation strategy (Yin, 2003), we used duplicate information sources to confirm the validity of the event information. Given the descriptive nature of this study and the lack of control over confounding factors, we did not try to draw causal relationships between events during data analyses. The analyses were focused on creating a precise account of China's drug R\&D evolution and the relevant institutional context.

\section{Results}

\section{Evolution of China's Drug Innovation}

Based on the pharmaceutical industry value curve (Bartlett \& Ghosal, 2000) and prior research into China's drug innovation (Lin, 2007; Zhang et al., 2009), China's drug R\&D evolution can be viewed to have four phases. Following Liang et al. (20II), we label these four phases as: (I) pure imitation, (2) innovative imitation, (3) imitative innovation, and (4) independent innovation. Please note that this analysis is based on Western medicine and does not include traditional Chinese medicine. In Phase I, pure imitation, the pharmaceutical firms fully depended on copying synthetic methods and preparation technologies of drugs from foreign companies. In Phase II, innovative imitation, China's drug innovation was mainly based on modifying delivery methods and preparation formulations of existing drugs without changing the drug molecular structure. In Phase III, imitative innovation, drug innovation was focused on chemical modifications of the structure of existing drugs, such as changing acid or basic group, altering optical configuration, and developing isomers of original drugs to develop "me-too" drugs. Finally, in Phase IV, independent innovation, Chinese companies will be able to discover new chemical entities (NCEs) using advanced innovation technologies.
As the drug R\&D and the IP policies have coevolved in China, the dates when different patent laws came into force can be used as ideal timeline anchors to delimit the four phases. As Table I shows, China enacted three patent laws in 1985, 1992, and 2008, respectively. Before 1985, China's pharmaceutical companies could legally copy any drugs from foreign countries. After the 1985 patent law which protected manufacturing processes of drug synthesis and dosage forms, companies could still imitate existing drugs, but they had to conduct low-level innovations to develop new synthesis methods or new dosage forms. Since thel 992 patent law started to grant full patent protection to drugs, the pharmaceutical companies could not imitate existing drugs without modifying their molecular structures. Thus, after 1992, they focused on developing "me-too" drugs which have minor structural differences from existing drugs. After the 2008 patent law entered into force, drug patent protection in China became more comprehensive and stronger, making it difficult to imitate existing drugs. Hence, in this period the best way for pharmaceutical companies to stay competitive would be to conduct independent innovations by discovering NCEs. 


\begin{tabular}{|lll|}
\hline Phase & $\begin{array}{l}\text { Patent law amendment } \\
\text { date }\end{array}$ & IP protection for drugs \\
\hline Pure imitation $(1949-1985)$ & $\mathrm{n} / \mathrm{a}$ & Protection of the synthesis and \\
& & $\begin{array}{l}\text { dosage form manufacturing } \\
\text { processes of pharmaceuticals only }\end{array}$ \\
Innovative imitation $(1984-1993)$ & March 12,1984 & Patent protection of drugs \\
Imitative innovation $(1992-2008)$ & September 4,1992 & Patent exemption for drugs trail \\
compulsory licensing and parallel & \\
Independent innovation $(2008-)$ & December 27, 2008 & import of patent drugs \\
\hline
\end{tabular}

Table I. Evolution of China's Intellectual Property Protection for Drugs

\section{Phase I: Pure Imitation (1949 - 1984)}

In 1949, China had approximately I50 small pharmaceutical factories, which could manufacture only over 40 types of drugs in small scales. Lacking production capacity and technologies, China could not even independently supply the six basic types of medicines: antibiotics, sulfonamides, antipyretic drugs, vitamins, endemic drug, and antituberculosis. In addition, China's pharmaceutical education was seriously underdeveloped. There was only one pharmaceutical college and a few pharmacy departments in medical colleges.

The Chinese government took a strategy of pure imitation and import to sustain the nation's fundamental medication needs. Pharmaceutical factories were encouraged to imitate patent drugs from foreign countries by reverse engineering and focus on expanding the pharmaceutical synthesis capacity. Meanwhile, the government allocated funds to establish of several large-scale state-owned pharmaceutical enterprises to produce antibiotics, sulfonamides, and antipyretic analgesics. While setting the focus on manufacturing bulk drugs, the government gave priority to the R\&D of antibiotics, sulfonamides, and other medicines which were widely used for preventing endemics and epidemics and desperately needed in rural regions. In the 1960s, a centralized leadership for the pharmaceutical industry was implemented, and under its guidance China's domestic pharmaceutical industry started to develop in a planned manner.

After over 30 years development, China's pharmaceutical industry became much stronger. In 1985, there were I,377 domestic pharmaceutical manufacturers in China, which hired 522,600 employees and created a gross output value of $\$ 1.56$ billion. The total output of chemical medicines was 5.76 ton, achieving a profit tax of $\$ 0.26$ billion and a sales amount of one billion dollars. The pharmaceutical production capacity could basically satisfy the domestic demand. Bulk drug manufacturing bases were firmly established and a great amount of experts and professionals in chemical synthesis were cultivated.

Before 1985, China had no patent law to protect IP rights of pharmaceutical products. The whole pharmaceutical industry was unaware of the importance of drug innovation. Almost all pharmaceuticals were directly copied from foreign companies. 
Moreover, China's drug R\&D investment was far less than that of developed countries. For example, in 1985 the drug R\&D expenditures in the U.S. were over $\$ 3.3$ billion, more than the total investment of science and technology innovations in China ( $\$ 3.1$ billion). In spite of 32 pharmaceutical research institutions and 5,692 researchers, China's overall drug innovation capability was insufficient for conducting advanced drug R\&D and far behind developed countries. In 1985, China had no universally recognized new chemical entity (NCE), whereas 26 NCE drugs were approved in the U.S.

\section{Phase II: Innovative Imitation (1985 - 1993)}

China started IP protection by enforcing its first patent law on April I, 1985. Along with the Drug Administration Law and the Trademark Law, the basic policy system for drug IP protection came into being. Meanwhile, in order to encourage innovations in the pharmaceutical industry, the Chinese government carried out a series of major national investment projects, such as the Spark Plan and the 863 Program, to give enterprises financial support for technology innovations. National policies also created a facilitating environment for pharmaceutical innovations. For example, "Provisional Regulations of the National Hi-tech Industry Development Zone Policies" (1991) provided tax benefits to hi-tech companies, including pharmaceutical companies.

With the establishment of an IP legal system, Chinese pharmaceutical companies started to realize the importance of innovations, and gradually increased R\&D investments. In this phase, the major approach to drug innovation was still based on imitating existing drugs. Different from pure imitation, some innovative features were added so that the new product was not a direct copy of the original drug. Yet these innovations are at a low level, mainly focused on drug delivery methods and preparation formulations. The new drug's molecular structure was exactly the same as that of the original drug. This was because (I) most Chinese companies lacked technology, experience, and capital to develop more advanced innovations, and (2) the Chinese IP policy did not prohibit imitating the molecular structure of existing drugs.

In this phase, the number of new drug approvals increased dramatically every year (Figure I). While in 1986 less than five new drugs were approved, 205 new drugs were approved in 1992. Although several Class-I drugs were approved every year, since China had a lower standard than the global standard, only one drug, artemisinin, was internationally recognized as a NCE.

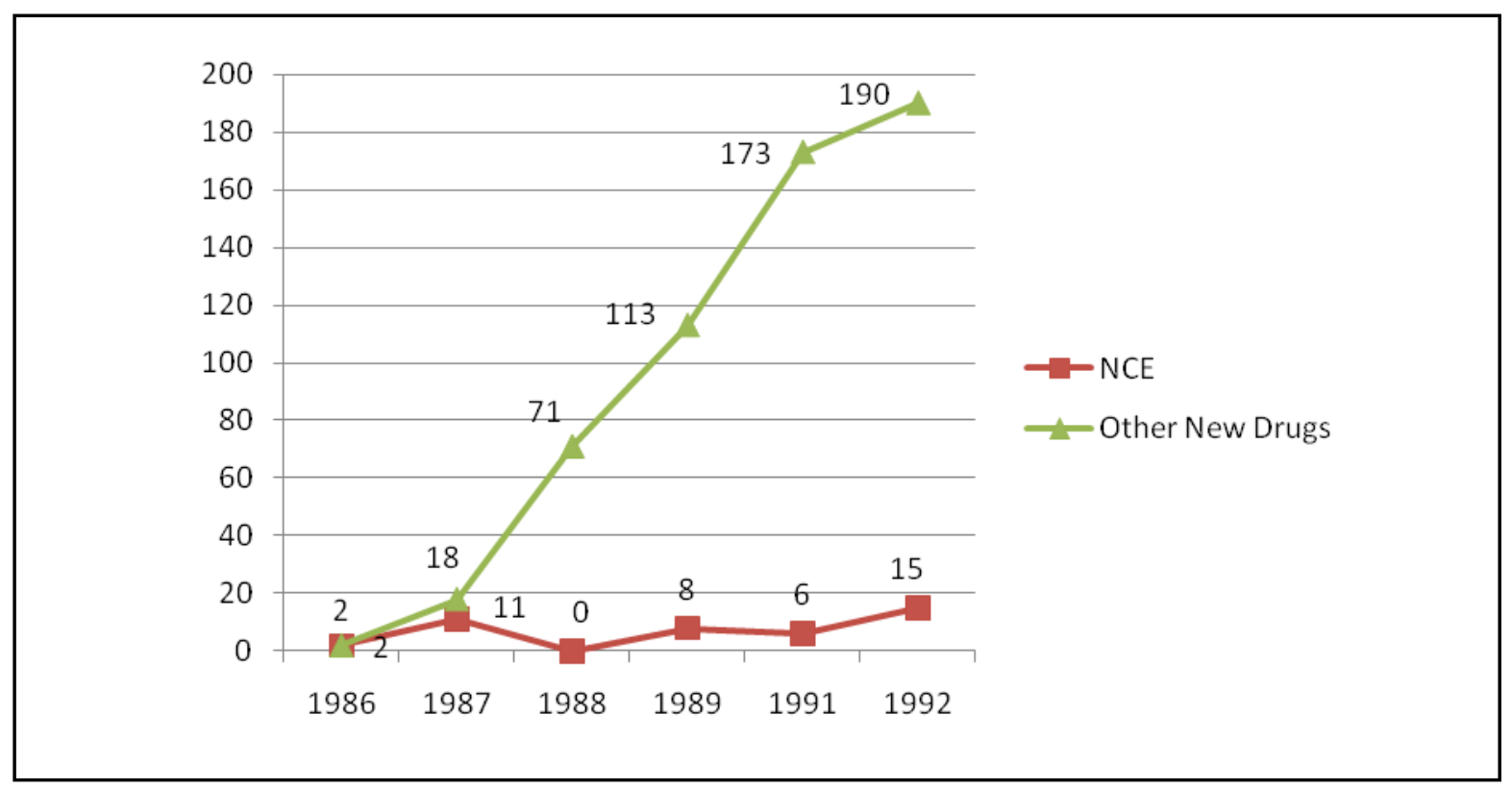

Figure I. Numbers of new drug approvals from 1986 to 1992 (Source: Chinese Medicine Yearbook)

ISSN: 07 I 8-2724. (http://www.jotmi.org)

Journal of Technology Management \& Innovation (c) Universidad Alberto Hurtado, Facultad de Economía y Negocios 


\section{Phase III: Imitative Innovation (1993 - 2008)}

To comply with TRIPS and prepare for entering the WTO, China amended its Patent Law in 1993 and 2000 respectively and revised the "Detailed Rules for the Implementation of the Patent Law" accordingly. These legislative changes signified China's strong IP protection. China's Patent Law provided protection for medical products, process, and products obtained by the patented process. The term of patent protection for a new drug is 20 years since the day of filing, during which no entity or individual may, without the authorization of the patentee, exploit the patent for production or business purposes.

To comply with TRIPS, the Trademark Law, amended in the year 1993 and 2001 respectively, provides a validity period of ten years for a registered trademark. Where the registrant intends to continue to use the registered trademark beyond the expiration of the validity period, an application for renewal of the registration shall be made within six months before the said expiration. The validity period of each renewal of registration shall be ten years. Though drugs are not compelled to have registered trademarks any more, the "well-know trademark" and "geographical indications" specified in the newly-amended
Trademark Law offer strong protection for the sales of new drugs. For example, compound radix pseudostellariae granule is developed from radix pseudostellariae, a natural product whose quality is the highest in Tuorong County in Fujian Province and geographical indications have provided strong protection for its sales against similar products from other regions ( $P a n \&$ Chen, 2009).

The Pharmaceutical Administration Law amended in 200I and Provisions for Drug Registration have legally defined new drug for the first time' ${ }^{\prime}$. They offer Data Exclusivity Protections to the applicant who obtains approval for production or distribution of the drug which contains any new chemical entity ${ }^{2}$.

During this period, the Chinese government implemented the 973 Project and National Science and Technology Major Project ${ }^{3}$ successively to encourage technology innovations. In addition, a series of tax exemption policies were enacted to spur technology innovations through reducing income taxes, value-added taxes, and business taxes related to technology innovations.

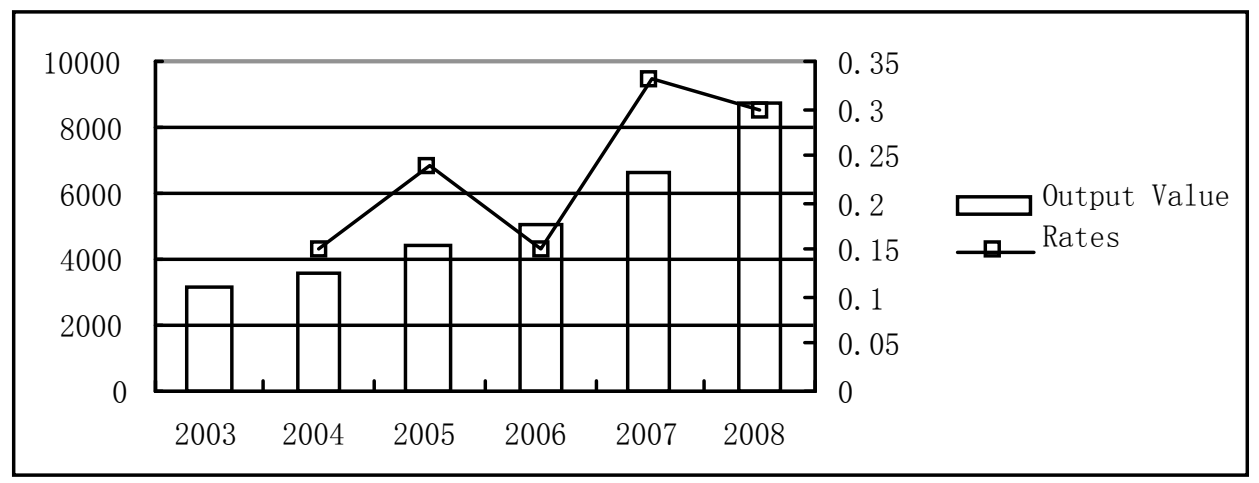

Figure 2. Growth of output values of the pharmaceutical industry in China (Source: Historical data sorted from China's high-tech industrial statistics yearbook)

'Article 12(I),(2) of Provisions for Drug Registration:Application for new drugs refers to the application for registration of drugs that has not been marketed within the territory of People's Republic of China. Application for changing dosage form or route of administration, or claiming a new indication for marketed drugs, shall be submitted as the process of new drug application. ${ }^{2}$ Article 20 of Provisions for Drug Registration: In accordance with the provisions in Article 35 of the Regulations for Implementation of the Drug Administration Law, where a manufacturer or distributor submits undisclosed drug experimental and other data which are independently acquired in order to obtain approval for production or marketing of the drug in question which contains any new chemical entity, the State Food and Drug Administration shall, within six years from the approval date of the drug, reject any application made by any other applicants by using the undisclosed data of the drug in question without permission of the original applicant who has obtained the drug approval, unless the data submitted are independently acquired by the applicants other than the original one. ${ }^{3}$ The National Science and Technology Major Project was confirmed in the National Program for Medium-term and Long-term Science and Technology development in January 2006 with special emphasis on 16 major projects, including major new drugs creation, control and prevention of major infectious disease.

ISSN: 07I8-2724. (http://www.jotmi.org)

Journal of Technology Management \& Innovation ( Universidad Alberto Hurtado, Facultad de Economía y Negocios 
During this period, China's drug production capacity was improved greatly with the output value of the pharmaceutical industry increased from $\$ 373$ billion in 2003 to $\$ 1220$ billion in 2008 . The pharmaceutical industry in China has demonstrated an accelerating development pattern since 2003. Influenced by the government's efforts in controlling bribes in pharmaceutical sales and rectifying the market order and a wave of drug price drop (Lu, 2006), the industry's growth ratio had a sudden decline in 2006. Nonetheless, the output value of 2006 is still about 15\% more than that of 2005 (see Figure 2).

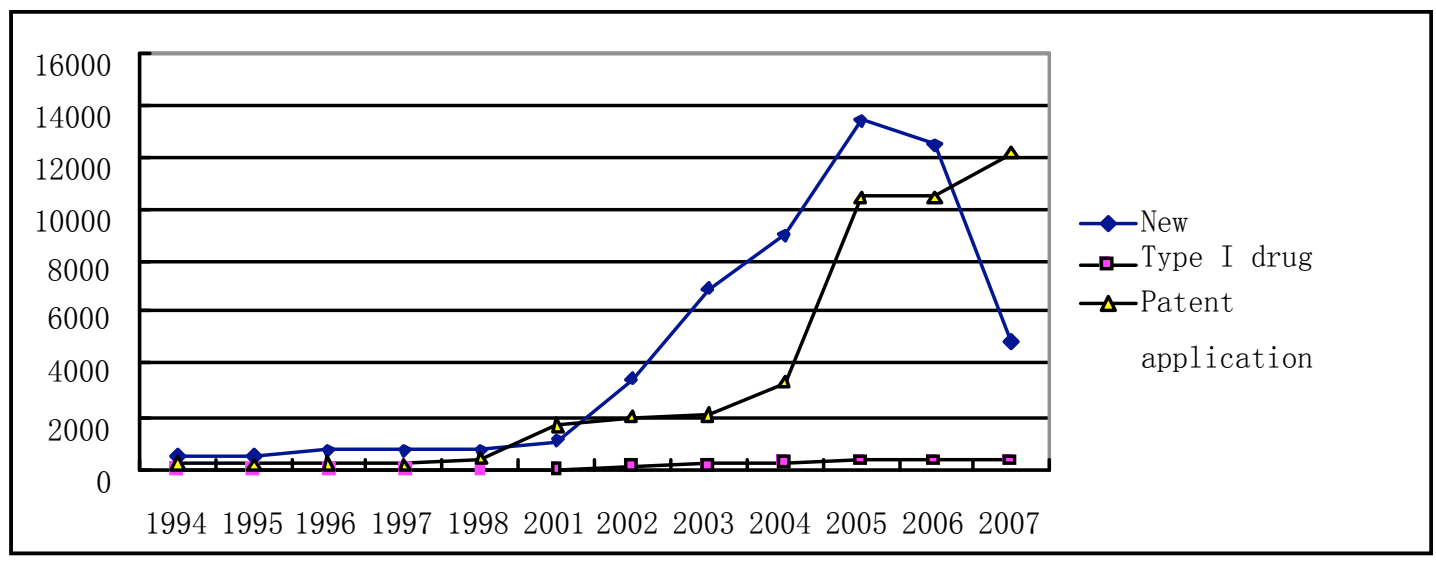

Figure 3. Volume of new drug approvals and patent applications filed from 1994 to 2007 (Source $\square$ China medicine yearbook)

As the market became increasingly globalized, Chinese enterprises fully realized the significance of innovations and made great improvement in drug R\&D capabilities. The number of new drugs marketed in 2007 is ten times as many as that in 1994. Although the high volume of new drug approvals (NDAs) indicates China's awareness of the importance of drug innovation, it should be noted that the volume itself cannot reflect China's real drug innovation capabilities because serious corruptions of the State Food and Drug Administration (SFDA) and China's low standard for new drugs contributed to the high volume (Liang et al., 201I). As shown by Liang et al. (20II), if the new drug standards of the United States are applied, China had only two NCEs from 2000 to 2008, while the United States had 193 NCEs in the same period. Since the new "Provisions for Drug Registration" was enacted on October Ist 2007, the SFDA had raised the entry threshold for drug registration and tightened the new drug approval standards, which greatly reduced the number and improved the quality of new drugs (Wang, 2009). As Figure 3 shows, the number of new drug approvals declined drastically from over 12,000 in 2006 to less than 5000 in 2007. The number of patent applications has been rising continuously with the improvement of the patent law. For instance, the number of applications in 2007 is over 200 times more than that in 1994. However, the amount of Class-I new drugs comparable to NCEs is rather low, just accounting for $6 \%$ of all the new drugs approved in 2007.

\section{Phase IV: Independent Innovation (2008-present)}

In 2008, China's drug R\&D expenditure was approximately $\$ 1.57$ billion and 37,200 R\&D personnel were involved. Compared with developed countries, however, China's drug R\&D input is still at a low level. In 2008, China's R\&D investment accounted for $1.33 \%$ of sales revenues, while USA, European Union (EU) and Japan spent more than $13 \%$ of sales revenues. R\&D personnel in those developed countries also outnumbered those in China. For input in drug R\&D, there is still a large gap between China and the developed countries (see Table 2). 


\begin{tabular}{|lcccc|}
\hline & China & America & EU & Japan \\
\hline Sales value (Billion dollars) & 117.91 & 286.01 & 247.36 & 77.30 \\
R\&D input (Billion dollars) & $1.57 *$ & 38.43 & 37.81 & $14.88 *$ \\
R\&D input / Sales value & $1.33 \%$ & $13.44 \%$ & $15.28 \%$ & $19.24 \%$ \\
Developers & $37241 *$ & 700000 & 117000 & \\
\hline
\end{tabular}

Table 2. Comparison of R\&D input between China and developed countries in 2008 (Sources: EFPIA, PhRMA, JPMA, China's high-tech industrial statistics yearbook))/* Based on the measurement results of the average growth rate of pharmaceutical R\&D expenditure in America, EU, Japan and China in 2000-2007

The SFDA received 165 new drug applications in 2008 most of which were formulation changing or dosing route changing of marketed drugs. Due to different definitions of new drug, the number of new drug applications in China is almost the sum of applications filed in EU, Japan, and U.S. in 2008. But EU and U.S. independently developed far more NCEs than China (Table 3). In 2008, China only had one NCE, laprazole, an agent to treat peptic ulcer. At present, China's drug R\&D capabilities still seriously lag behind developed countries. In addition, in 2008 the State Intellectual Property Office (SIPO) of China received 9259 drug patent applications, more than those in EU and U.S., suggesting the heightening of awareness of IP protection in China.

\begin{tabular}{|lcccc|}
\hline & China & USA & Japan & EU \\
\hline New drug applications & 165 & 31 & 77 & 66 \\
NCE & 1 & 21 & 3 & 6 \\
Drug patent applications & 9259 & 5051 & 8962 & 6041 \\
\hline
\end{tabular}

Table 3. Comparison of drug R\&D output between China and developed countries (Source: Annals of FDA, EMEA, PMDA, SFDA in 2008, USPTO, EPO, JPO, SIPO, China's patent database)

\section{National drug innovation strategy and policy}

The national innovation policies with the core of the IPR policy have played an important role in guiding China's drug R\&D. Prior research shows that a nation's drug innovation level and its relevant policies mutually influence each other (Ding \& M, 2009; Yang et al., 2007; Zhang et al., 2008). The basic principle of China's drug innovation policy is embodied in two fundamental national strategies: building an innovative country and establishing intellectual property rights. In 2006, the 17th National Congress of Chinese Communist Party emphasized that enhancing independent innovation capabilities and constructing an innovative country are the core of China's national development strategy, which are crucial for improving China's comprehensive national power. This is the first time the Chinese government includes the concept of innovation in its national development strategy. In 2008, the Chinese State Council issued 
“National Intellectual Property Strategy Compendium", asserting that China would be transformed into a country with high level of creating, utilizing, protecting and administrating intellectual properties by 2020 . China's national drug innovation policy system consists of relevant laws, regulations and policies promulgated under the national strategy, which is intended to stimulate independent drug innovations. Based on different executing agencies and mechanisms of policy tools, this system can be described as having three major components: the core IPR policy, the drug regulatory policy, and other related national policies (Figure 4).

China's policy
innovation for drug $\left\{\begin{array}{l}\text { The Core IPR policy } \\ \text { Drug regulatory policy }\left\{\begin{array}{l}\text { Patent review and approval } \\ \text { Patent administration } \\ \text { Patent protection }\end{array}\right. \\ \text { Other related policies }\left\{\begin{array}{l}\text { Drug regulatory approval } \\ \text { Drug pricing } \\ \text { Compensation of essential medicines }\end{array}\right. \\ \left\{\begin{array}{l}\text { Scientific and technological input policy } \\ \text { Tax incentive policy } \\ \text { Monetary policy } \\ \text { Venture capital policy } \\ \text { Research incentive policy }\end{array}\right.\end{array}\right.$

Figure 4. China's policy system for drug innovation

\section{Core Intellectual Property Policy}

The core IP policy is a collection of laws and regulations on IPR. The state IP office and its branches are the main executing agents (Liu, 2009). The legal system of IP in China includes patent, trademark and copyright laws, among which the patent law (the new patent law enacted on Octoberl, 2009) is the most influential one on drug R\&D.

The new patent law adopted the international standard of novelty examination to conduct drug patent review and approval so that innovative drugs made in China are competitive in the global market. In terms of drug patent administration, new clauses of parallel importing, compulsory licensing and drug trail and application exemption (Bolar exception) are added. To enforce drug patent protection, the new patent law increased administrative penalties for patent violations. Temporary injunctions before a lawsuit of patent infringement are also specified by the law to provide stronger protection for the IPR owner's benefits.

\section{Drug regulatory policy}

China's drug regulatory policy centers on Drug Administration Law and Provisions for Drug Registration. Its objective is to ensure drug safety, efficacy, quality and accessibility. The State Development and Reform Commission (SDRC), SFDA and their branches are the main executing agents. Given the significant impact of drugs on national health care, strict regulatory policies have been formulated to control the market approval and pricing of drug products. While strict procedures and criteria are set by law to review and approve new drugs, the Chinese government opens a special "green channel" for new drugs independently developed by domestic organizations and orphan drugs to shorten the review time. 
SDRC promulgated the Drug Pricing Measures (draft), which proposes higher prices for patented drugs than generic drugs. The purpose is to help firms get return on investments in drug R\&D. Besides, according to the draft implementation of national essential drugs policy, new drugs with better cost-effectiveness are planned to be added into the National Essential Drugs List, so the inventing pharmaceutical companies can be compensated for their R\&D investment. However, it should be noted that drug pricing is a complicated issue and could distort market incentives and inappropriately reward physicians' overprescribing (Sun et al., 2008).

\section{Other related policies}

The Chinese government has implemented a series of policies in various areas such as science and technology input and tax preference to encourage technology innovations in the pharmaceutical industry. Aiming to realize the national strategy of improving the capability of independent innovation and building an innovative country, the Chinese government has activated a national program, Major New Drug Creation, proposing a budget of almost one billion dollars to support domestic pharmaceutical companies to develop new drugs with independent IPR. The government has been steadily increasing funding to support drug R\&D activities of the domestic pharmaceutical industry. For example, the large pharmaceutical firms' R\&D expenditures supported by the government increased from about $\$ 125,000$ in 2002 to $\$ 3 \mid 3,000$ in 2007. In addition, the Chinese government applied tax reduction for high technology industry, including pharmaceutical industry. Pharmaceutical firms are eligible for exemption of income and sales taxes for their drug R\&D expenses.

\section{Discussion}

The results suggest that China's national policies have played a significant role in developing an innovationfriendly context within which the nation's drug innovation capabilitiesare expected to befostered.Anin-depthanalysis reveals five trends of China's drug R\&D environment.

\section{Balance between patent and accessibility}

Although new drugs are discovered to help human beings counter health threats, these new drugs are usually protected by IPR and too expensive for people with an ordinary income. The Chinese government has realized the paradox and started to alleviate this problem through policy adjustments. The clauses of compulsory licensing and drug trail exemption in the new patent law are the first steps taken in this direction. China is also reforming its essential drug list to ensure that the public has access to basic medicines.

\section{Stricter drug review process}

SFDA disclosed at the beginning of 2009 that the principle of its future drug review and approval work would be to use strict standards to identify innovative and high quality drugs. In the past, SFDA had limited technical capacity to ensure the quality of NDAs. To remove loopholes in original data verification and production process inspection, the "Provisions for Drug Registration" requires that new drug R\&D should be under whole process monitoring and the authenticity, accuracy and completeness of original records should be confirmed onsite (Zhao et al., 2009). The government will continue to enforce effective drug administration with strict review and approval procedures, which is expected to guide pharmaceutical companies to form a scientific attitude towards drug R\&D and increase drug quality.

\section{Shorter drug approval time}

Time required for clinical trials and drug approvals in China is expected to become shorter. From the early 1990 s to the early 2000 s, the average time for clinical trials declined from 79.5 to 63.2 months, and the average time for drug approval dropped from 31.3 to 18.4 months (Wang \& Kang, 2005). At present $\square$ the NDA approval duration is from 12 to 18 months (Chenoweth, 2005). SFDA will continue to improve the mechanism of drug review and approval in the coming years by increasing review efficiency and communications between applicants and the approving agency.

\section{Heavier government investment}

To accelerate the implementation of the strategy of building an innovative country, the NDRC issued the Eleventh Five-Year plan which is focused on developing China's fundamental capacity of independent innovation. As a special project under the umbrella of the Eleventh Five-Year plan, Major New Drug Creation aims to develop a series of innovative drugs for 10 major diseases such as malignant tumors and cardiovascular diseases with a budget of about US\$I billion. It is expected to greatly improve the innovation capability of China's pharmaceutical industry. The 12-year project was officially started in May 2008 and includes three 
phases. It is estimated that the funding for this project will increase from $\$$ I billion to about $\$ 4.3$ billion by 2020 (Ren, 2009). The Chinese government is determined to strengthen its drug innovation by pouring financial resources and this trend will continue for years to come.

\section{More extensive regional integration}

Atpresent, China's pharmaceuticalindustryischaracterized by small companies scattered in many regions, leading to insufficient resource sharing and cooperation and inadequate integration of competencies within districts. In 2009, China has 488I drug manufacturers that produce more than 12,000 categories of medicines and many of their products are low-level duplicates. Regional agglomeration of the pharmaceutical industry can help to solve these problems and it is also conducive to attracting specialized talents and venture capital needed by R\&D (Mao, 2006). The Chinese government has issued a series of policies such as financial support and tax preference offered to major innovation projects within pharmaceutical industrial clusters. At the end of 2007, the SDRC issued national proposals to guide the development of industrial clusters. Responding to the SDRC proposal, many regional biopharmaceutical industrial cluster development plans and biopharmaceutical technology parks have been developed. The technology parks have demonstrated healthy growth. In the next few years, more pharmaceutical industrial clusters are expected to emerge.

\section{Conclusion}

This study shows that drug innovation in China has evolved from pure imitation to a stage where independent innovation is desirable and possible. During the course of evolution, the government has played a significant role by issuing various policies, laws, and strategies to cultivate and spur the domestic drug R\&D. A valuable lesson for other developing countries is that in order to improve drug innovation capabilities the government has to get highly involved. Without an innovation-friendly policy environment, drug innovation will be difficult to prosper. Moreover, this study presents a detailed account of China's policy system relevant to drug innovation. With an understanding of the complex policies and their implications for drug R\&D, international investors will be able to make better informed decisions when they attempt to operate pharmaceutical businesses in China.

\section{Acknowledgement}

This work was supported by the State Intellectual Property Office of China (SS09-A-26: Research on incentive and protection policies on R\&D of innovative drugs). The writing of this article is independent of the funding source.

\section{References}

BARTLETT, C. A., \& Ghosal, S. (2000). Going global: lessons from late movers. Harvard Business Review, 78(2), $132-142$.

CHENOWETH, D. (2005). Is more really less in China's new drug approvals? Drug Discovery Today, I0(17), II40-II42.

DING, J., \& M, Z. (2009). The comparative study on supervision and incentive policies of Sino-US during the innovative drug R\&D. Chinese Journal of New Drugs, 387-392 (in Chinese).

DU, G. (2005). Current situation and countermesures of IPR in pharmaceutical enterprises. Capital Medicine, 1214 (in Chinese).

GRANT, R. M. (1996). Toward a Knowledge-Based Theory of the Firm. Strategic Management Journal, 17, 109-122.

LI, Q. (2007). Research on Technology spillover effect by Foreign Direct Investments' on China's pharmaceutical industry. University of International Business \& Economics.

LIANG, H., Ding, J., \& Xue, Y. (20II). China's drug innovation and policy environment Drug Discovery Today, I6(I-2), I-3.

LIN, B. (2007). Competition strategy for imitation and generic drugs. China Youth Science and Technology, 2I-24(in Chinese).

LIU, C. (2009). Law of Intellectual Property. Beijing: Publishing House of Renmin University of China.

LU, P. (2006). Will Pharmaceutical Industry meet with the low margin age? Dynamics of reform on Drug Prices is still being strengthened. Retrieved November 12, 2009, from http://biz.cn.yahoo.com/06/124/36/jzt4.html 
MAO, J. (2006). Industry agglomeration and human capital accumulation: the cases of Yangtze Delta and Pearl Delta Journal of Beijing Nomal University, 103-110 (in Chinese).

PAN, W., \& Chen, L. (2009). Radix Pseudostellariae of Tuorong County being developed as drugs for pediatric usage. Retrieved January 2I, 2010, from http://www.zgycsc.com/readinfo-htm-ifid-31902.html

REN, Y. (2009). The best time for drug R\&D is coming. Capital Medicine, 16(13), 22-24 (in Chinese).

SUN, Q., Santoro, M. A., Meng, Q., Liu, C., \& Eggleston, K. (2008). Pharmaceutical policy in China. Health Affairs, 27(4), 1042-1050.

WANG, L. (2009). SFDA new drug applications decreased quantity while increased quality Retrieved November 12, 2009, from http://info.pharmacy.hc360. com/2009/09/09101489948.shtml

WANG, L., \& Kang, C. (2005). Research on strategic alliance in pharmaceutical enterprises. Science and Technology Management Research, III-II3 (in Chinese).

YANG, L., Li, Y., \& Xu, Y. (2007). Incentive Policies on innovative drug R\&D in U.S. Chinese Journal of $\mathrm{New}$ Drugs, 985-988 (in Chinese).

YIN, R. K. (2003). Case Study Research Design and Methods (3 ed. Vol. 5). Thousand Oaks: Sage Publications.

ZHANG, X. T., Ping, Q. N., \& Hu, B. (2008). A view on correlative factors for the drug innovation system in the US with enlightenments to China. Chin J New Drugs Clin Rem., 27(10), 795-800 (in Chinese).

ZHANG, X. T., Q.N., P., \& L.H, A. (2009). The development of the pharmaceutical industry in India and its influencing factors. China Pharmaceutical, 495-498 (in Chinese).

ZHAO, J., Zhang, X. D., Xu, L., \& Mao, W.J. (2009). Features of the Revision of Provisions for Drug Registration and Its Effect on Drug R\&D. Pharmaceutical Journal of Chinese People's Liberation Army, 280-282 (in Chinese). 
J. Technol. Manag. Innov. 20II,Volume 6, Issue 2 